\title{
Modular Approach to Implement Model Predictive Control on Three Phase Voltage Source Inverter
}

\author{
Muhammad Abbas Abbasi ${ }^{1}$, Abdul Rashid Bin Husain ${ }^{2}$, Hasan Alqaraghuli ${ }^{3}$ \\ ${ }^{1,2,3}$ Department of Control and Mechatronics Engineering, Universiti Teknologi Malaysia (UTM), Malaysia \\ ${ }^{1}$ The Islamia University of Bahawalpur, Pakistan
}

\begin{tabular}{|c|c|}
\hline Article Info & ABSTRACT \\
\hline Article history: & A modular abstraction is presented to implement model predictive control \\
\hline Received Dec 21, 2017 & $\begin{array}{l}\text { (MPC) on a three phase two level voltage source inverter to control its output } \\
\text { current. Traditional ways of coded implementation do not provide insights }\end{array}$ \\
\hline Revised Jan 22, 2018 & into the complex nature of MPC; hence a more intuitive, logical and flexible \\
\hline Accepted Feb 7, 2018 & $\begin{array}{l}\text { approach for hardware implementation is conceptualized in the form of } \\
\text { signal flow graphs (SFGs) for estimation, prediction and optimization. }\end{array}$ \\
\hline Keyword: & $\begin{array}{l}\text { Simulation results show good performance of the approach and easier code } \\
\text { generation for real time implementation. RL load is assumed for the inverter }\end{array}$ \\
\hline $\begin{array}{l}\text { Current control } \\
\text { Model predictive control }\end{array}$ & $\begin{array}{l}\text { and the importance of choosing load inductance and sampling time ratio is } \\
\text { emphasized for better control performance. }\end{array}$ \\
\hline
\end{tabular}

Modular MPC

Three phase inverter

Copyright $@ 2018$ Institute of Advanced Engineering and Science. All rights reserved.

\section{Corresponding Author:}

Abdul Rashid Bin Husain,

Department of Control and Mechatronics Engineering,

Universiti Teknologi Malaysia (UTM)

81310 Skudai, Johor, Malaysia

Email: abrashid@utm.my

\section{INTRODUCTION}

Three phase two level voltage source inverters are widely used in power electronics applications especially in drive control [1], [2]. Controlling output current of such inverter topologies is also widely researched topic. Model predictive control (MPC) is emerging as the most promising digital control method in the field of power electronics and drive applications. It has extensively been studied for induction and synchronous motor drives, front end rectifiers, multilevel inverters, and DC-DC converters [3], [4]. MPC demand higher computational costs and its applications will rapidly increase in the field of power electronics with the advent of high speed microprocessors and digital signal processors. MPC provide numerous benefits over traditional control methods such as easier handling of system constraints, parameter variations and easier incorporation of control tasks in the optimization cost function [5]-[7]. Most of the control strategies treat converters to be linearized systems ignoring their highly nonlinear nature. MPC takes this factor into account.

A model based predictive control for VSI is presented and discussed in detail in [1]. A space vector (SV) representation is used to model and analyze the system. An RL load and a simple back EMF model is used to investigate the performance of the controller. Controller consists of three stages of implementation i.e. estimation of back EMF, prediction of future currents, and optimization of a cost function involving current error. The estimation and prediction is based on Euler's forward approximation formula and prediction horizon of 1 is assumed.

Most of the controller applications are implemented in the form of $\mathrm{C}$ codes, making the working and troubleshooting of the controller obscure and difficult. Instead of directly implementing the control scheme in the form of codes, a signal flow graph representation and automatic code generation of the controller is 
suggested here for easier modifications, understanding and implementation. A module based SFG will make it also possible to adopt model referencing for incorporating prediction horizon greater than 1 by simply repeating the appropriate modules. Tustin discretization rule is adopted for better results and a prediction horizon equal to 2 is used. Moreover the role of a special resistance L/Ts is elaborated with simulation results as a gain factor.

In the first section, mathematical model of inverter and load is presented. In section II, detailed discussion on the proposed MPC approach is given, followed by simulation results and conclusion in section III and IV respectively.

\section{INVERTER AND LOAD MODEL} Figure 1.

The inverter and load model is adopted from [8]. The circuit diagram of the system is shown in

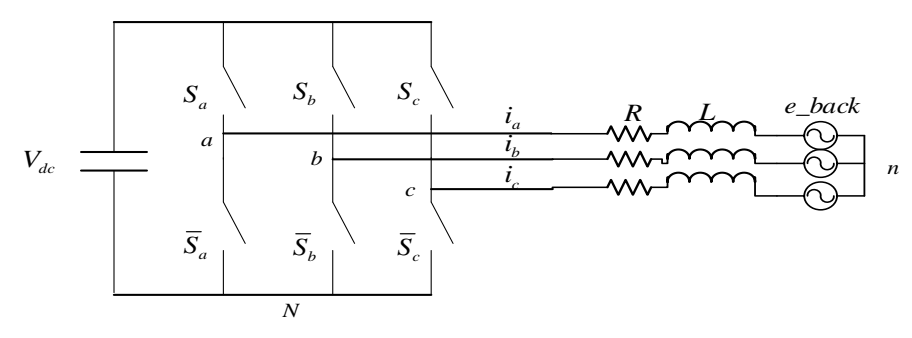

Figure 1. Three phase voltage source inverter with RL load

A dc source feeds the inverter with a constant supply voltage $V_{d c}$. Switches of the inverter are operated in bipolar fashion i.e. no two switches in the same leg are turned ON or OFF simultaneously. Therefore the lower switches are represented with a complimentary symbol. Inverter is driving a three phase RL load with a sinusoidal back EMF $e_{-}$back . A space vector representation will be assumed throughout the discussion. Space vector for three phase quantities $x, y$ and $z$ is defined as:

$s v\{x, y, z\}=\frac{2}{3}\left(x+y e^{\frac{j 2 \pi}{3}}+z e^{\frac{j 2 \pi}{3}}\right)$

The inverter voltage space vector can be defined as:

$S v\left\{v_{a N}, v_{b N}, v_{c N}\right\}=\frac{2}{3}\left(v_{a N}+v_{b N} e^{\frac{j 2 \pi}{3}}+v_{c N} e^{\frac{j 2 \pi}{3}}\right)$

Where

$$
\begin{aligned}
& v_{a N}=S_{a} V_{d c} \\
& v_{b N}=S_{b} V_{d c} \\
& v_{c N}=S_{c} V_{d c}
\end{aligned}
$$

Based on (2) and (3) a table (Table 1) of inverter voltage vectors can be generated for each possible switching state. Note that $v_{0}=v_{7}=0$ lie on the origin. Voltage vectors are shown in Figure 2.

The load equation in the form of space vectors can be written as [9]:

$$
v=i R+L \frac{d i}{d t}+e_{-} \text {back }
$$

Following vectors are assumed in (4): 
$v=s v\left\{v_{a N}, v_{b N}, v_{c N}\right\}$

$i=s v\left\{i_{a}, i_{b}, i_{c}\right\}$

$e_{-} b a c k=s v\left\{e_{-} b a c k_{a}, e_{-} b a c k_{b}, e_{-} b a c k_{c}\right\}$

\section{MODULAR MPC CONTROLLER}

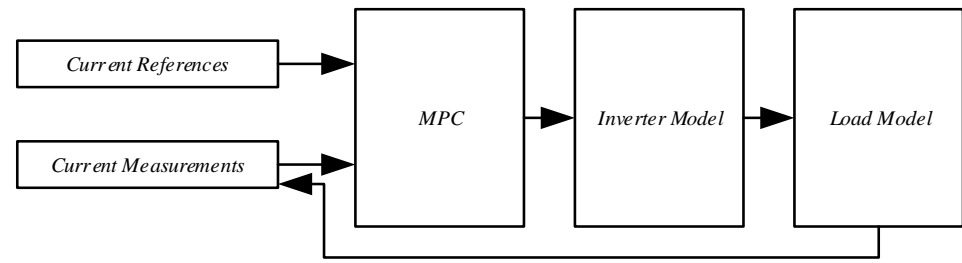

Figure 2. Traditional implementation of MPC

Table 1. Inverter Switching States and Resulting Voltage Vectors

\begin{tabular}{lllll}
$k$ & $S_{\alpha}$ & $S_{b}$ & $S_{c}$ & $v_{k}$ \\
\hline 0 & 0 & 0 & 0 & 0 \\
\hline 1 & 1 & 0 & 0 & $\frac{2}{3} V_{d c} \angle 0^{\circ}$ \\
\hline 2 & 1 & 1 & 0 & $\frac{2}{3} V_{d c} \angle 60^{\circ}$ \\
\hline 3 & 0 & 1 & 0 & $\frac{2}{3} V_{d c} \angle 120^{\circ}$ \\
\hline 4 & 0 & 1 & 1 & $\frac{2}{3} V_{d c} \angle 180^{\circ}$ \\
\hline 5 & 0 & 0 & 1 & $\frac{2}{3} V_{d c} \angle 240^{\circ}$ \\
\hline 6 & 1 & 0 & 1 & $\frac{2}{3} V_{d c} \angle 300^{\circ}$ \\
\hline 7 & 1 & 1 & 1 & 0 \\
\hline
\end{tabular}

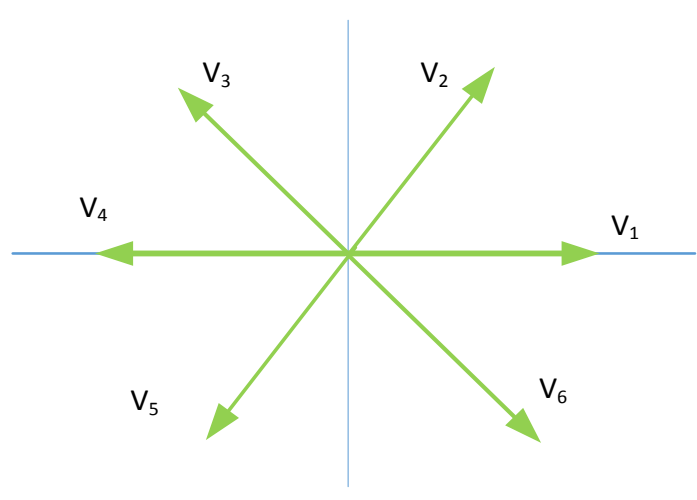

Figure 3. Voltage vectors

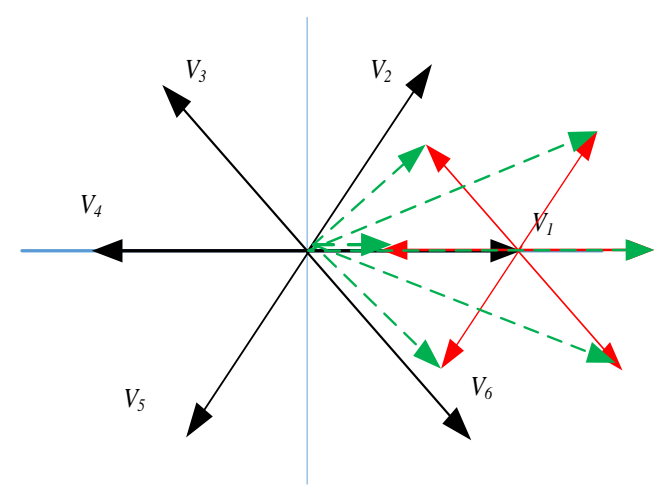

Figure 3. Voltage Vector addition for prediction horizon $\mathrm{N}=2$ 
For predicting currents, we can discretize (4) using Euler's forward rule $\frac{d y(t)}{d t} \approx \frac{y(k+1)-y(k)}{T_{s}}$ to get the following approximation [10]:

$$
i(k+1 \mid k)=\left(1-R / R_{o}\right) i(k)+R_{o}\left(v(k)-e_{-} \operatorname{back}(k)\right)
$$

Where $i(k+1 \mid k)$ is the predicted value of current, one sampling step into the future $k+1$ and the prediction is made at time instant $k \cdot R_{o}=L / T_{s}$ is a special ratio and can be changed by changing the sampling time $T_{s}$ [11]. Note that $v(k)$ can take 7 values depending upon the switching combination applied to the inverter. We will assume all the possible switching states to predict 7 values of the current and choose the best switching state which produces minimum current error.

For better performance, we will assume prediction horizon equal to 2 . Therefore, at time instant $k+2$ the current can be predicted to be:

$$
i(k+2 \mid k)=\left(1-R / R_{o}\right) i(k+1 \mid k)+R_{o}\left(v(k+1)-e_{-} \text {back }(k+1)\right)
$$

Since back EMF is slow varying, therefore we can safely assume $e_{-}$back $(k+1) \approx e \_b a c k(k)$. Putting (6) into (7) with $c_{1}=\left(1-\frac{R}{R_{o}}\right)$ and $c_{2}=R_{o}$ and simplifying:

$$
i(k+2 \mid k)=c_{1} i(k)+c_{2}\left(\underline{c_{1} v(k)+v(k+1)}\right)-\left(c_{1} c_{2}+c_{2}\right) e_{-} \text {back }(k)
$$

The underlined part in (8) is significant since it represents the voltage vector addition to predict current two instants into the future. Each vector from $v_{0}$ to $v_{6}$ is added to the scaled version of entire vector space. Ignoring $v_{0}$ addition, we can anticipate 36 sums. This situation is shown for $v_{1}$ addition in fig. 4 . Note that $\mathrm{c} 1$ is less than 1 , therefore the added vectors are smaller in lengths. In the same way we can get all the sums and evaluate $(8)$ for different vectors. Number of sums can further be reduced by considering the fact that $R_{o}$ is larger than $R$ which will give $c_{1} \approx 1$.

For better estimation of back EMF, we will use Tustin's Bilinear Transformation [12] i.e. $s=\frac{2}{T}\left(\frac{1-z^{-1}}{1+z^{-1}}\right)$. Applying Laplace transform on (4) will result in:

$V=R I+s L I+E_{-}$back

After discretization:

$E_{-}$back $=\left(1-z^{-1}\right) V-\left(R+2 R_{o}\right) I-\left(R-2 R_{o}\right) z^{-1} I+z^{-1} E \_b a c k$

$z^{-1}$ represents unit delay and the system is assumed relaxed. Based on equation (6) and equation (10) the implementation block diagrams are shown in Figure 5 and Figure 6. These block diagrams can be separately implemented for real and imaginary parts of the system or multiplexed as a vector. 


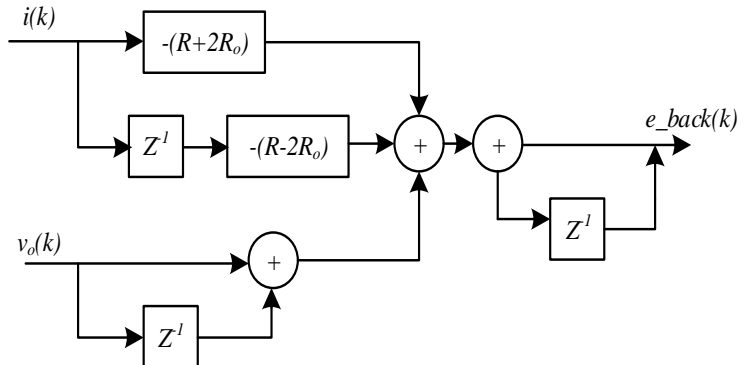

Figure 4. Back EMF estimation module

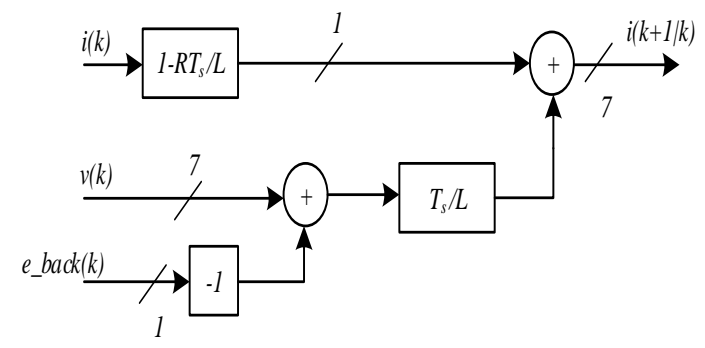

Figure 5. Current Prediction

We can repeat the prediction module twice to get the predictions $i(k+2 \mid k)$ and the process can be extended to further predictions easily. However, the number of computations will increase $N^{2}$ times. There are various techniques available to reduce these calculations.

After prediction and estimation, we have to choose the best switching state to be applied at the next sampling interval based on the following cost function.

$$
g=\sum_{N=1}^{2}\left\|i_{r e f, \alpha}(k+N)-i_{\alpha}(k+N \mid k)\right\|+\left\|i_{r e f, \beta}(k+N)-i_{\beta}(k+N \mid k)\right\|
$$

Here, the currents are referred to the stationary $\alpha \beta$ frame. Assuming that we choose $N=1$, from fig. 6 , we see that there are 7 predictions for current at time instant $k+1$, hence 7 values of cost function in (11) can be obtained by the implementation shown in Figure 7. The diagram uses basic building blocks available in most simulation software for code generation. After the calculation of 7 error values between future reference current and 7 predicted currents, their absolute value is computed. Next block finds the minimum absolute error $\left(g_{-}\right.$opt $)$. To find the voltage vector which produces this minimum error, we compare $g_{\text {_ opt }}$ with all the other values. Only one comparison produces 1 which is multiplied with the index values to determine optimal state state_opt to be applied at next sampling interval. For prediction horizon greater than 1 , this module can easily be replicated as required. The overall implementation block diagram is shown in Figure 8.

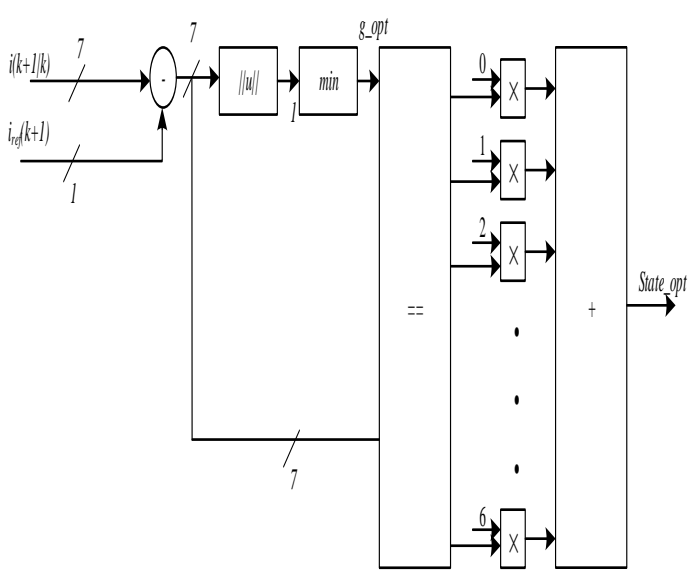

Figure 6. Selection of optimal switching states

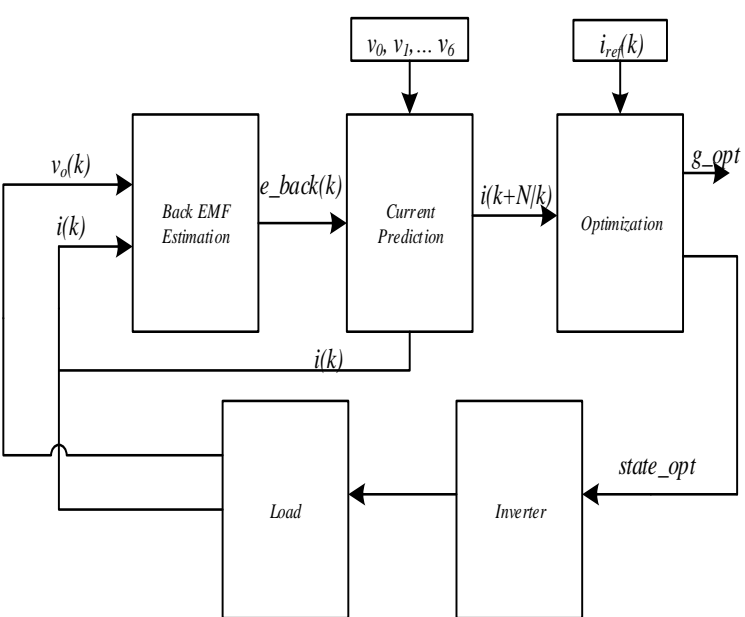

Figure 7. Implementation Block Diagram 


\section{SIMULATION RESULTS}

The proposed modular approach is implemented in Matlab/Simulink for $L=10 m H, R=8 \Omega$. Peak amplitude of back EMF is assumed to be $120 \mathrm{~V}$ and frequency of $50 \mathrm{~Hz}$ while DC source of $450 \mathrm{~V}$ is considered. Figure 9 shows the simulation results of output currents for a sinusoidal reference of amplitude $12 \mathrm{~A}$ and frequency $50 \mathrm{~Hz}$, for two different values of sampling time i.e. $100 \mu \mathrm{s}$ and $20 \mu \mathrm{s}$. Since decreasing the value of sampling time will require a higher switching frequency, it will significantly increase the quality of the output currents at the same time giving a boost to the computational demands. Practically, it becomes computationally heavier to use smaller values of sampling time. Therefore a compromise is made while choosing the sampling time for less distorted current waveforms.
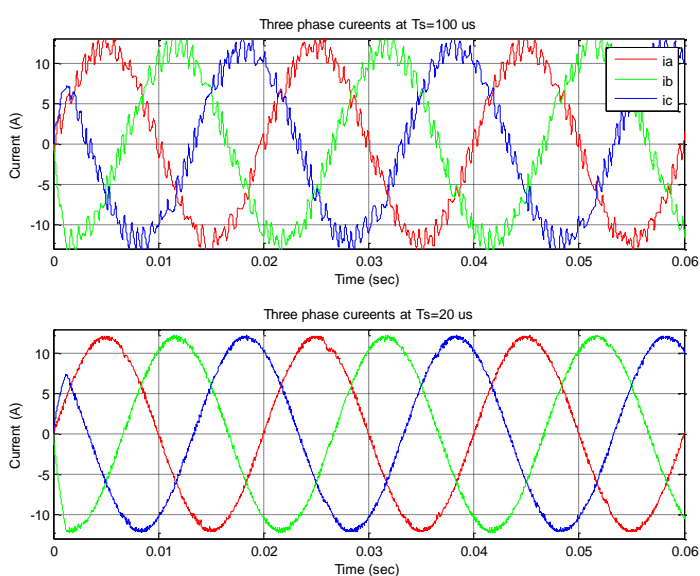

Figure 8. Effect of sampling time on output current
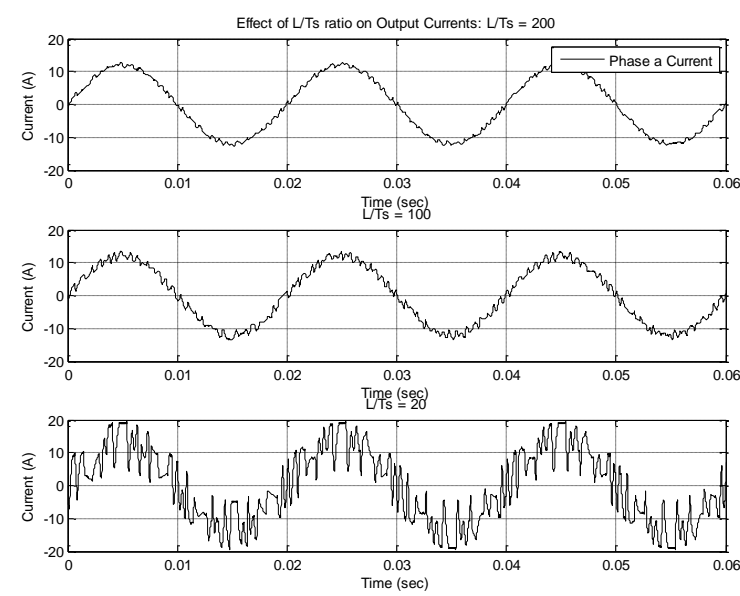

Figure 9. Effect of L/Ts ratio on output currents

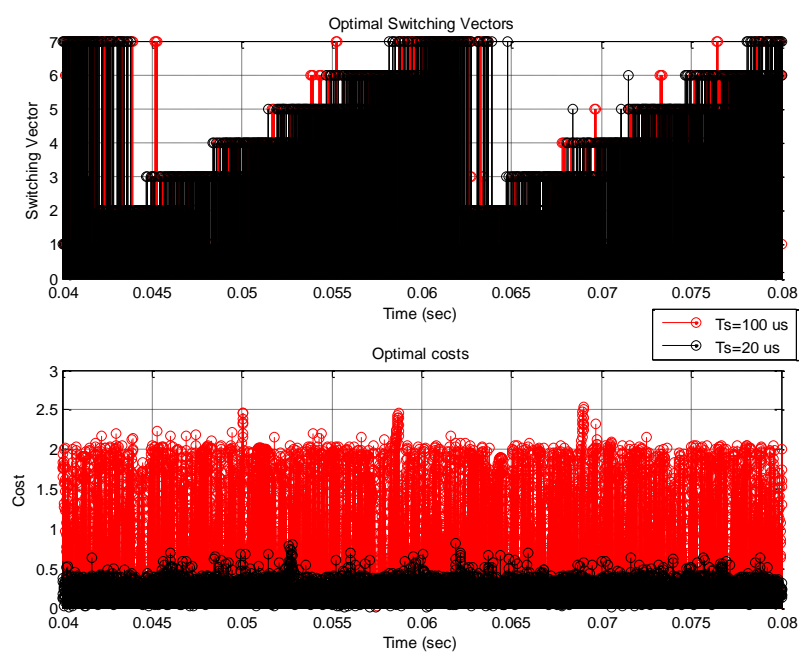

Figure 10. Optimal states and cost function for different values of sampling time

Figure 10, on the other hand shows the effect of the ratio L/Ts on the current waveforms. Only single phase current is showed to explain the effect. If the ratio is kept higher i.e. $T_{s}$ smaller, current waveforms are less distorted. If we decrease the ratio by increasing $T_{s}$, the current THD increases and distortions occur. If this ratio becomes equal to $\mathrm{R}$, current predictions are purely made on the basis of estimated back EMF and voltage vectors. For better results, this ratio should be kept around 100 to 200 .

Finally Figure 11 gives the plots of the optimal costs and optimal states calculated by the MPC controller for a limited frame of time. There is no significant effect of sampling time on the optimal states 
chosen for the inverter, however optimal costs are significantly reduced when smaller sampling times are used.

\section{CONCLUSION}

A modular way to interpret and implement model predictive control (MPC) for a three phase two level inverter is investigated. The basic stages involved in MPC implementation are broken down to simple modules based on SFGs and fundamental building block found in all digital control implementation and simulation software. The approach provides more intuition, flexibility and ease of code generation and modification of the MPC hardware implementation. This approach can be easily extended to incorporate higher prediction horizons and complex discretization methods for estimation. Future work may involve the extension of the approach to other applications such as drive control, increasing the prediction horizon by using vector representation and reduction of effective switching states through state transition diagrams.

\section{ACKNOWLEDGEMENTS}

Authors would like to acknowledge Universiti Teknologi Malaysia (UTM), The Islamia University of Bahawalpur (IUB) Pakistan and Higher Education Commission (HEC) of Pakistan for providing financial support to conduct this research.

\section{REFERENCES}

[1] J. Rodriguez, J. Pontt, C. A. Silva, P. Correa, P. Lezana, P. Cortes, and U. Ammann, "Predictive Current Control of a Voltage Source Inverter," Ind. Electron. IEEE Trans., vol. 54, no. 1, pp. 495-503, 2007.

[2] P. Cortés, M. P. Kazmierkowski, R. M. Kennel, S. Member, D. E. Quevedo, and J. Rodríguez, "Predictive Control in Power Electronics and Drives," IEEE Trans. Ind. Electron., vol. 55, no. 12, pp. 4312-4324, 2008.

[3] A. Iqbal, S. Moinoddin, and K. Rahman, "Finite State Predictive Current and Common Mode Voltage Control of a Seven-phase Voltage Source Inverter," Int. J. Power Electron. Drive Syst., vol. 6, no. 3, 2015.

[4] G. Mirzaeva, G. C. Goodwin, B. P. McGrath, C. Teixeira, and M. E. Rivera, "A Generalized MPC Framework for the Design and Comparison of VSI Current Controllers," IEEE Trans. Ind. Electron., vol. 63, no. 9, pp. 5816-5826, 2016.

[5] K. Shen and J. Zhang, "Modeling error compensation in FCS-MPC of a three-phase inverter," in PEDES 2012 IEEE International Conference on Power Electronics, Drives and Energy Systems, 2012.

[6] H. H. Goh, A. Aida, S. S. Lee, S. Y. Sim, and K. C. Goh, "Predictive Direct Power Control ( PDPC ) of Gridconnected Dual-active Bridge Multilevel Inverter ( DABMI )," Int. J. Power Electron. Drive Syst., vol. 8, no. 4, pp. 1524-1533, 2017.

[7] S. H. Yusoff, N. S. Midi, S. Khan, and M. Tohtayong, "Predictive Control of AC / AC Matrix Converter," Int. J. Power Electron. Drive Syst., vol. 8, no. 4, pp. 1932-1942, 2017.

[8] A. Boulahia, M. Adel, and H. Benalla, "Predictive Power Control of Grid and Rotor Side converters in Doubly Fed Induction Generators Based Wind Turbine," Int. J. Electr. Comput. Eng., vol. 3, no. 3, 2013.

[9] S. Vazquez, A. Marquez, J. I. Leon, L. G. Franquelo, and T. Geyer, "FCS-MPC and Observer Design for a VSI with Output LC Filter and Sinusoidal Output Currents," in Compatibility, Power Electronics and Power Engineering (CPE-POWERENG), 2017 11th IEEE International Conference on, 2017, pp. 677-682.

[10] S. Bolognani, S. Bolognani, L. Peretti, and M. Zigliotto, "Design and Implementation of Model Predictive Control for Electrical Motor Drives," IEEE Trans. Ind. Electron., vol. 56, no. 6, pp. 1925-1936, 2009.

[11] F. Barrero, M. R. Arahal, R. Gregor, S. Toral, and M. J. Durán, "One-step modulation predictive current control method for the asymmetrical dual three-phase induction machine,” IEEE Trans. Ind. Electron., vol. 56, no. 6, pp. 1974-1983, 2009.

[12] M. Habibullah, D. D.-C. Lu, D. Xiao, J. E. Fletcher, and M. F. Rahman, "Low complexity predictive torque control strategies for a three-level inverter driven induction motor," IET Electr. Power Appl., vol. 11, no. 5, pp. 776-783, 2017. 


\section{BIOGRAPHIES OF AUTHORS}
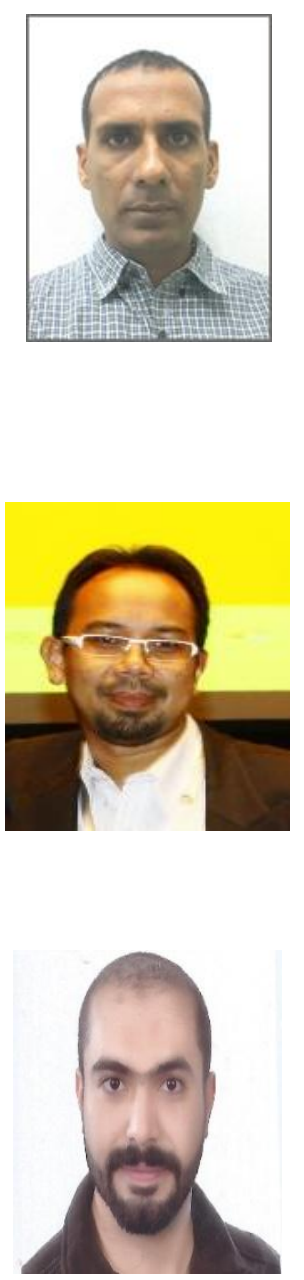

Muhammad Abbas Abbasi received his B.Sc. degree in Electronics Engineering from The Islamia University of Bahawalpur, Pakistan in 2004 and M.S. degree in Electrical Engineering from University of Engineering \& Technology (UET), Taxila, Pakistan in 2012. Currently he is pursuing his PhD degree in Universiti Teknologi Malaysia (UTM). He is a full time faculty member at The Islamia University of Bahawalpur, Pakistan and has also worked in different control industries in Pakistan. $\mathrm{He}$ has taught courses in Control Engineering, Digital Signal Processing, FPGA based system Design and Electronics Systems. His research interests include Model Predictive Control of Power Converters and Drives, Predictive Direct Torque Control, FPGA based Control, and Signal Processing.

A. R. Husain received the B.Sc. degree in electrical and computer engineering from The Ohio State University, Columbus, Ohio, U.S.A., in 1997, M.Sc. degree in Mechatronics from University of Newcastle Upon Tyne, U.K., in 2003, and Ph.D. in Electrical Engineering (Control) from Universiti Teknologi Malaysia (UTM) in 2009. Before joining UTM, he worked as an engineer in semiconductor industry for several years specializing in precision molding and IC trimming process. He has taught courses in introduction to electrical engineering, microcontroller based system, modeling and control, electric motor and drives, and real-time control system. His research interests include control of dynamic system, real-time control system, and mechatronic system design.

Hasan Alqaraghuli received the B.S. degree from University of Technology, Baghdad, Iraq, in 2014 and the MEng degree from Universiti Teknologi Malaysia, Johor Bahru, Malaysia, in 2016. He is currently working towards the Ph.D. degree in Universiti Teknologi Malaysia, Johor Bahru, Malaysia. His research interests include model predictive control, motor drives, sensorless control of AC motors and electrical vehicle. 